\title{
E-tourism Usage Patterns of Tourism Business in Chiang Mai, Thailand
}

\author{
Paisarn Kanchanawong, Chodok Charungkon, Songsak Poonoi \\ Maejo University, Chiang Mai, Thailand
}

\begin{abstract}
The main objective of this research was to study the pattern and suggestion in ICT usage of tourism business in Chiang Mai. One hundred ninety questionnaires, referred from ICT usage pattern in organization which was divided into three sections: office work, communication/contacts and public relation/advertising, were gathered from tourism business in four districts in Chiang Mai. Results showed that of the tourism business only $54.7 \%$ have their own websites. Using ICT for public relations and advertisement purpose, hotel/accommodation was the highest users with majority as $29.3 \%$; followed by tour operator with majority as $26.3 \%$; transportation and souvenir was the lowest number of users with minority as $50.0 \%$ and $25.0 \%$. For communication purpose, hotel/accommodation business and tour operator business were high users with majority as $56.1 \%$ and $43.4 \%$; followed by restaurant business as moderate user with majority as $50.0 \%$; and transportation business as the lowest user with minority as $31.1 \%$. The paper suggested to owners of tourism businesses the following: (1) training on ICT application; (2) setting up center of tourism information; (3) low cost of internet requirement from small tourism business because they lack technical person on ICT usage. Both the local and national governments should have important roles in supporting the small and medium tourism enterprises by providing good public facilities, technical expertise and easy information access.
\end{abstract}

Keywords: ICT for tourism, e-tourism, Chiang Mai

\section{Introduction}

\section{Background}

Chiang Mai, a city and the center of tourism in the north of Thailand ranking second to Bangkok, is famous to millions of local and foreign tourists (The Tourism Authority of Thailand, 2010). However in the past two years, the number of foreign tourists had decreased due to the unstable political situation. Many tourism businesses have closed and at the same time new tourism businesses are established. The use of information and communication technology or ICT has been a helpful tool for the tourism businessmen, especially in promoting the business and contacting tourist/clientele and facilitating confirmation of the tourists.

Paisarn Kanchanawong, Ph.D., Lateral, School of Tourism Development, Maejo University.

Chodok Charungkon, MS, Lateral, School of Tourism Development, Maejo University.

Songsak Poonoi, MS, Lateral, School of Tourism Development, Maejo University.

Correspondence concerning this article should be addressed to Paisarn Kanchanawong, School of Tourism Development, Maejo University, 63 Moo 4, T. Nonghan, A.Sansai, Chiang Mai 50290, Thailand. E-mail: paisarn@mju.ac.th. 
Using ICT in tourism businesses in Chiang Mai as used similarly around the world is one strategy in developing tourism business conforming to the policy of the Tourism Authority of Thailand (TAT) 2007-2011 or developing ICT for tourism (e-tourism) an important policy to improve the efficiency of promoting Thailand (The Tourism Authority of Thailand, 2009). Therefore, the study of e-tourism in Chiang Mai will serve as a basic knowledge on the use of ICT in managing and promoting tourism businesses in Chiang Mai that can push forward towards the efficiency of promoting tourism in Chiang Mai and Thailand as a whole.

\section{Objectives of the Study}

(1) To study the mode of using ICT for tourism of tourism businesses in Chiang Mai;

(2) To study the suggestions on using ICT for tourism in the tourism business organization of Chiang Mai.

\section{Scope of the Study}

(1) The researcher studied the use of ICT for tourism in tourism business in three models: (a) use of ICT in the office work; (b) use of ICT for communicating or contacting; and (c) use of ICT for public relations and advertising;

(2) The researcher studied the tourism businesses in Chiang Mai according to five categories: (a) accommodations; (b) tour operators; (c) transportations; (d) restaurants; and (e) souvenirs;

(3) The researcher conducted the study for 11 months from January to November 2010;

(4) The location of the population used in the study was the tourism businesses in the city district of Chiang Mai and the nearby districts of Hangdong, Saraphee, Sansai, Sankhamphaeng, and Mae Rim in Chiang Mai province;

(5) In terms of variables there are 11 variables of general information of respondents, variables on models of using ICT for tourism in three aspects as 14 variables or totaling 25 variables.

\section{Research Method}

\section{Population and Sample}

The population in this study is from the tourism business sectors in Chiang Mai totaling 472 businesses (The Tourism Authority of Thailand, 2010a, 2010b, 2010c; HotelsThailand.com, 2010; Thailand Yellow Pages, 2010) classified into five types as follows: (1) accommodations; (2) tour operators; (3) transportation; (4) restaurants; and (5) souvenirs. Using simple random sampling following the five types of businesses, the size of sample was composed of 222 business units (Thaweerat, 1988).

\section{Pre-testing of Tool}

Questionnaire was developed based on framework of ICT in business application covering three areas such as: (1) office work and management; (2) communication and contacts; and (3) public relations, advertisement, marketing and services. The closed type questionnaire is divided into three parts, namely, general information of respondents, ICT usage pattern of tourism business using Likert scale, and suggestions. The questionnaire was pre-tested from unselected sampling of tourism business sectors in Chiang Mai for its content validity and obtained Cronbach's alpha coefficient of 0.799-0.954.

\section{Collection of Data}

Two hundred and fifty questionnaires were distributed, 213 were retrieved and 190 were accepted for 
statistical analyses. It was $40.25 \%$ from total (76\% returned rate).

\section{Statistical Analyses}

By using descriptive statistics frequency, percentage, average, standard deviation, highest and lowest values were calculated and interpreted to ICT usage patterns.

\section{Results and Discussion}

\section{Size of Business}

Kim (2004, pp. 1-8) stated that globalization has brought the changes so that a small tourism business could have less tourists than big business. Using ICT can promote and gather tourists from all over the world. The researcher has come up with new variable on the size of business based on the average of persons in the work from research results (18.3) and size of SME (Small and Medium Enterprise Institute, 2010) which can be classified into three sizes as follows: (1) business with 1-20 persons (83.2\%); (2) business with 21-50 persons (10.0\%); and (3) business with 51 and above persons (6.8\%) and showed that majority of tourism businesses are small sized businesses.

\section{New Enterprises}

Gratzera and Winiwarterb (2003) stated that threat of new comers was high investments but using ICT to promote the business was the lowest cost. The new enterprises in tourism business for the past 1-2 years (20.5\%) are classified into three groups, namely, tour operators (46.2\%), hotels (17.9\%), and transportation (10.3\%).

\section{ICT Usage Pattern of Tourism Business}

For overall of ICT usage patterns for tourism, it was at moderate level (3.15) where the level of using in office work was highest (3.30) followed by communication and contacts (3.24) and lowest on public relations and advertisement (2.91). The forms of ICT usage patterns of tourism businesses were classified as follows (see Table 1).

Tour operators: It showed that majority used ICT in office work at high level (48.5\%); communication and contracts at moderate level (43.4\%); and public relations and advertisement at low level (26.3\%).

Table 1

Levels in Number and Percentage of ICT Applications According to Type of Work in Tourism Businesses

\begin{tabular}{|c|c|c|c|c|c|c|c|c|c|c|c|c|c|c|c|}
\hline \multirow{3}{*}{$\begin{array}{l}\text { Type of tourism } \\
\text { business/type of } \\
\text { work }(n=190) \\
\text { Scale of use }\end{array}$} & \multicolumn{15}{|c|}{ ICT applications for tourism/e-tourism } \\
\hline & \multicolumn{4}{|c|}{ Office work } & \multicolumn{5}{|c|}{ Communication/contacts } & \multicolumn{6}{|c|}{ Publication/advertisement } \\
\hline & lowest & low & moderat & high & highest & lowest & low & moderat & high & highest & lowest & low & moderat & high & highest \\
\hline \multirow[t]{2}{*}{ Tour operator } & 1 & 9 & 36 & 48 & 5 & 1 & 11 & 40 & 43 & 4 & 9 & 23 & 23 & 26 & 18 \\
\hline & $1.0 \%$ & $9.1 \%$ & $36.4 \%$ & $48.5 \%$ & $5.1 \%$ & $1.0 \%$ & $11.1 \%$ & $40.4 \%$ & $43.4 \%$ & $4.0 \%$ & $9.1 \%$ & $23.2 \%$ & $23.2 \%$ & $26.3 \%$ & $18.2 \%$ \\
\hline \multirow{2}{*}{$\begin{array}{l}\text { Accommodations/ } \\
\text { hotels }\end{array}$} & 1 & 2 & 19 & 17 & 2 & 0 & 6 & 11 & 23 & 1 & 5 & 5 & 10 & 9 & 12 \\
\hline & $2.4 \%$ & $4.9 \%$ & $46.3 \%$ & $41.5 \%$ & $4.9 \%$ & $0 \%$ & $14.6 \%$ & $26.8 \%$ & $56.1 \%$ & $2.4 \%$ & $12.2 \%$ & $12.2 \%$ & $24.4 \%$ & $22.0 \%$ & $29.3 \%$ \\
\hline \multirow[t]{2}{*}{ Transportation } & 4 & 5 & 5 & 2 & 0 & 5 & 3 & 4 & 4 & 0 & 8 & 2 & 1 & 2 & 3 \\
\hline & $25.0 \%$ & $31.3 \%$ & $31.3 \%$ & $12.5 \%$ & $.0 \%$ & $31.3 \%$ & $18.8 \%$ & $25.0 \%$ & $25.0 \%$ & $0 \%$ & $50.0 \%$ & $12.5 \%$ & $6.3 \%$ & $12.5 \%$ & $18.8 \%$ \\
\hline \multirow[t]{2}{*}{ Souvenirs } & 0 & 6 & 9 & 5 & 0 & 2 & 7 & 6 & 5 & 0 & 5 & 5 & 4 & 4 & 2 \\
\hline & $0 \%$ & $30.0 \%$ & $45.0 \%$ & $25.0 \%$ & $0 \%$ & $10.0 \%$ & $35.0 \%$ & $30.0 \%$ & $25.0 \%$ & $0 \%$ & $25.0 \%$ & $25.0 \%$ & $20.0 \%$ & $20.0 \%$ & $10.0 \%$ \\
\hline \multirow[t]{2}{*}{ Restaurants } & 0 & 2 & 10 & 1 & 1 & 0 & 2 & 7 & 5 & 0 & 4 & 3 & 5 & 2 & 0 \\
\hline & $0 \%$ & $14.3 \%$ & $71.4 \%$ & $7.1 \%$ & $7.1 \%$ & $0 \%$ & $14.3 \%$ & $50.0 \%$ & $35.7 \%$ & $0 \%$ & $28.6 \%$ & $21.4 \%$ & $35.7 \%$ & $14.3 \%$ & $0 \%$ \\
\hline \multirow[t]{2}{*}{ Total } & 6 & 24 & 79 & 73 & 8 & 8 & 29 & 68 & 80 & 5 & 31 & 38 & 43 & 43 & 35 \\
\hline & $3.2 \%$ & $12.6 \%$ & $41.6 \%$ & $38.4 \%$ & $4.2 \%$ & $4.2 \%$ & $15.3 \%$ & $35.8 \%$ & $42.1 \%$ & $2.6 \%$ & $16.3 \%$ & $20.0 \%$ & $22.6 \%$ & $22.6 \%$ & $18.4 \%$ \\
\hline
\end{tabular}


Accommodations/hotels: It showed that majority used ICT in office work at moderate level (46.3\%); communication and contracts at high level (56.1\%); and public relations and advertisement at highest level (29.3\%). This could be due to online reservation available through the websites of the hotels/accommodations or direct contacting by the clientele.

Transportation: It showed that majority used ICT in office work at low level and moderate level (31.3\%); communication and contracts at lowest level (31.3\%); and public relations and advertisement at lowest level.

Souvenirs: It showed that majority used ICT in office work at moderate level (45.0\%); communication and contracts at low level (35.0\%); and public relations and advertisement at low and lowest levels (25.0\%).

Restaurant: It showed that majority used ICT in office work at moderate level (71.4\%); communication and contracts at moderate level (50.0\%); and public relations and advertisement at moderate level (35.7\%).

\section{Compared With International Tourism Business}

From the results on having websites, it found that more than half (54.7\%) have websites for their own businesses, and majority of these were on tour operators (61.5\%) followed by accommodations (26.0\%), souvenirs (4.8\%), transportation (3.8\%), and restaurants (3.8\%).

Tourism businesses using computers comprise $95.3 \%$ of which $53.0 \%$ is tour operators followed by accommodations (22.1\%) and lastly restaurants (7.7\%).

The statistics in terms of using computers (95.3\%), having websites (54.7\%) about the tourism businesses in Chiang Mai at present are comparable to the small and medium enterprises in the global level (see Table 2) in the past nine years. Thus, the government should give support in terms of providing know-how in new technology, online advice to update and sustain the tourism businesses in Chiang Mai.

Table 2

Percentage of Using ICT and Having Websites of Tourism Business in Chiang Mai Compared With Other Countries

\begin{tabular}{lll}
\hline Country & Using ICT in 2001 (\%) & With own websites in 2001 (\%) \\
\hline Australia & 92 & 53 \\
Denmark & 95 & 62 \\
Spain & 91 & 6 \\
Greece & 98 & 58 \\
Sweden & 84 & 28 \\
England & 96 & 67 \\
Germany & 92 & 49 \\
Luxemburg & 96 & 65 \\
Netherlands & 90 & 39 \\
Italy & 87 & 31 \\
Norway & 86 & 9 \\
Chiang Mai (Thailand) & 93 (in 2010) & 47 (in 2010) \\
\hline
\end{tabular}

Note. Source: Applied from Buhallis and Deimezi (2004).

\section{Suggestions for Tourism Businesses in Using ICT for Tourism}

The researcher collected suggestions and opinions from a total of 67 questionnaires or $13.67 \%$ and summarized as follows: 
(1) The government sector or educational institutions should seek experts and hold trainings for tourism businesses especially the small and medium size businesses which lack people with ICT know-how and capital for advertisement. Training program should compose of using internet for advertisement, making website for the business, ICT application for tourism and other techniques using the computer in business, E-commerce, other forms of media/techniques in promoting tourism in Chiang Mai, data base for e-tourism, law on culture and history for accurate presentation to the tourists, and world tourism. Trainings should be given to all and not only to selected tourism businesses regularly;

(2) The government sector can give support in terms of providing free high speed internet services and other services to the tourists coming to Chiang Mai. They should support computer software to the businesses in order to standardize the information such as hotel software, car rental software, tourism software, and advertisement software which allow the government controls efficiently the tourism in Chiang Mai. Support of software is in the form of open sources and supports the private sector in allowing them to use the software to decrease costs of copyright payment. The taxes should be decreased especially taxes of hotels that pay the software copyright and the high costs of maintenance and system advancement;

(3) The government should be interested in improving and expanding the tourism in Chiang Mai by having a common websites for tourism in Chiang Mai and having a server with quality;

(4) The government officers should think of the interest of the common good provide safety to the tourists and politicians should keep the political situation calm or steady;

(5) The government should build good facilities for the convenience of the tourists such as good public transportation system (public bus and train) and provide for travel safety. Information service on tourist destinations should be efficiently accessible. Entrance fees to tourist places and tour operator fees should be standardized and give copyright protection to tour operators. Regular meetings of tourism businessmen would be helpful in bringing progress to Chiang Mai and websites should be censored to protect the youth.

\section{Development of Tourism Businesses}

The study found that three types of tourism businesses having computers and websites using cross tab form are as follows:

(1) High potential: having computers and websites (54.2\%) can develop by training their staff on updates on ICT know-how and skills at regular basis. Using the internet to decrease cost of promotion, improving the websites with updated and reliable information, keeping customers intact as a database and e-commerce can be done. Seeking partnerships from marketing and networking for information exchange and knowledge to expand database on selling product and services is done;

(2) Medium potential: having computers but without websites (41.1\%), having websites but without computers $(0.5 \%)$ can develop by training staff and managers on updates in e-commerce know-how and skills towards global level enterprise;

(3) Low potential: having no computers and websites (4.2\%) should support or persuade staff and managers on using ICT in the business and make budget plan and structure of ICT for office work.

\section{Conclusion}

The usage patterns of ICT in Tourism Business in Chiang Mai Based are drawn as follows: 
(1) The majority of tourism business in Chiang Mai is small business which has a staff from 1-20 persons and new comers, opened $1-2$ years, is $20.5 \%$;

(2) It found that more than half $(54.7 \%)$ have websites for their own businesses, and majority of these were on tour operators (61.5\%) followed by accommodations (26.0\%), souvenirs (4.8\%), transportation (3.8\%), and restaurants (3.8\%);

(3) The statistics in terms of using computers (95.3\%), having websites (54.7\%) about the tourism businesses in Chiang Mai at present are comparable to the small and medium enterprises in the global level in the past nine years;

(4) The level of using ICT in office work was highest followed by communication and contacts and lowest on public relations and advertisement;

(5) The Government sector should support training course, free high speed internet services and a common websites for small tourism business;

(6) Three types of tourism businesses, high, medium and low potential, having computers and websites are managed by the government.

\section{References}

Buhalis, D., \& Deimezi, O. (2004). E-tourism developments in Greece: Information communication technologies adoption for dimitrios Buhalis, Maria Cristina Licata, 2001. The Future E-tourism intermediaries. Retrieved from http://epubs.surrey.ac.uk/1126/1/fulltext.pdf

Gratzera, M., \& Winiwarterb, W. (2003). A framework for competitive advantage in e-tourism. Retrieved from http://homepage.univie.ac.at/werner.winiwarter/enter2003.pdf

HotelsThailand.com. (2010). Hotel in Thailand. Retrieved from http://hotelsthailand.com/

Institute for Small and Medium Enterprises Development. (2010). What is SMEs. Retrieved from http://www.ismed.or.th/SME/src/bin/controller.php?view=faq.FAQDetailInsite

Kim, C. (2004). E-tourism: An innovative approach for the small and medium-sized tourism enterprises (SMEs) in Korea. Retrieved from http://www.oecd.org/dataoecd/56/13/34268048.pdf

Thailand Yellow Pages. (2010). Search yellow pages. Retrieved from http://www.yellowpages.co.th/

Thaweerat, P. (1988). Researches on behavioral and social sciences. Bangkok: Charoenpol Printing Press (Thai version).

The Tourism Authority of Thailand. (2009). The policy of the Tourism Authority of Thailand (TAT) 2007-2011. Retrieved from http://thai.tourismthailand.org/about-tat/about-tat-24-1.html

The Tourism Authority of Thailand. (2010a). Chiangmai. Retrieved from http://thai.tourismthailand.org/where-to-go/cities-guide/destination/chiang-mai

The Tourism Authority of Thailand. (2010b). Restaurants in Thailand. Retrieved from http://thai.tourismthailand.org/where-to-eat/where-to-eat/

The Tourism Authority of Thailand. (2010c). Place to shopping in Thailand. Retrieved from http://thai.tourismthailand.org/where-to-shop/where-to-shop/

The Tourism Authority of Thailand. (2010d). Accommodation in Chiang Mai. Retrieved from http://thai.tourismthailand.org/where-to-go/cities-guide/accommodation/destination/chiang-mai/ 